\title{
Sexualidade humana - Caminhos e descaminhos
}

Mabel Cavalcanti*

Creio que falar sobre esses temas é dar prioridade à Vida. Vida na sua qualidade global. Isto porque entendo o Sexo como expressão da Vida, e podemos dizer que sob seu tríplice aspecto - Reprodução, Prazer e Comunicação Amorosa - esse fato é verdadeiro.

Do ponto de vista reprodutivo, Sexo é Vida, uma vez que a Reprodução perpétua a Vida.

Do ponto de vista prazeroso, Sexo e Vida estão interligados porque a Vida sem o mínimo de prazer não tem sentido. Enquanto vivemos estamos buscando nossas satisfações e extraindo dessa busca, o máximo de prazer possível.

É uma busca consciente da aquisição dessas satisfações, embora algumas vezes, isso que julgamos hoje, nossas satisfação, venha a ser a nossa destruição futura, principalmente quando, como seres humanos responsáveis, destruímos egoisticamente pessoas, apenas para que essa satisfação própria, imediatista seja alcançada. Isso é

* Psicóloga. Terapeuta sexual. Diretora do CESEX - Brasília. D.F. 
próprio da miséria humana. Exemplo disso são: o estupro, a violência sexual, as infidelidades e muitos outros casos. Não é desse sexo-prazer que eu me refiro.

Finalmente, como expressão do Amor, o Sexo é a própria manifestação da vida plena, que infelizmente nem todos conseguem atingir, ora bloqueados pelos ditames rígidos de sexo para reprodução, ou então desenfreados e na busca insana dos prazeres imediatos, cada vez mais Fáceis e sedutores do mundo atual.

Vamos tentar então fazer uma avaliação, um levantamento de cada um desses tópicos.

Sexo Reprodução: Não resta dúvida que, do ponto de vista filogenético a finalidade cósmica do sexo é a sobrevivência da espécie. Por isso mesmo, a natureza nos dotou de uma força interior capaz de exigir satisfação.

Esse processo, contudo, não surgiu por acaso no Universo. Ele é fruto de milhões e milhões de anos, levando-se em conta a evolução da espécie e a própria seleção natural.

Se no início da vida, os organismos simples sobreviviam assexuadamente, com o evoluir do processo, organismos mais fortes e mais complexos foram surgindo e exigindo uma força mais sofisticada de perpetuação.

A reprodução sexuada passou a ser um fim em si mesmo. Os seres sexuados teriam que se reproduzir rapidamente afim de que a espécie não desaparecesse sobre a terra. $\mathrm{O}$ nascimento tinha que superar a Morte e o sexo passou a ser o instrumento fundamental para que o projeto da Vida se tornasse vitorioso.

Mas, a reprodução sexuada não era tão simples. Ela exigia um certo número de condições. E a primeira delas é que haveria necessidade de um mínimo de comunicação, ou seja, um mínimo de contato entre os sexos. Para que houvesse PROLE, o macho teria que fecundar a fêmea.

Nos organismos hermafroditas, esse contato era feito consigo mesmo, mas, à medida em que os seres se tornavam mais complexos, as exigências aumentavam.

E aí surge uma outra condição necessária à sobrevivência:

- um dos sexos deveria ser responsável pela gestação e pelos cuidados posteriores com a prole. A natureza concedeu à fêmea, esse encargo. Neste estágio, o macho era apenas o inseminador. Mas, é a fêmea que vai ter um papel decisivo na seleção genética, porque não será qualquer macho que ela vai aceitar. 
Esse macho tem que ser um vencedor (o mais forte, o mais veloz, o que ostenta major beleza, etc...). Por isso nesmo nem todos os machos se reproduziam conseguindo deixar para a posteridade, sua mensagem genética. As fêmeas, pelo contrário. invariavelmente tinham lugar na sobrevivência da espécie.

Mas, a luta pela manutenção da vida e pela perfeição dessa Vida, não terminava por aí. Quanto mais complexa se tornava a vida animal, outros fatores colaboravam para o enriquecimento dessa vida. O macho começava a ser convocado para outras funções dentro do grupo: defender a progênie, supri-la de alimentos, ensinar-lhes (através de comportamentos imitativos), algumas artes de defesa e sobrevivência.

$O$ sexo reprodutivo aí começava a se enriquecer com outros atributos. Darwin explica que o desenvolvimento de certos caracteres anatômico, surgiram nesta época, possivelmente para representar a supremacia e vigor do macho, tais como: a grande e poderosa pinça do caranguejo, os aguçados dentes de um lobo ou mesmo os enormes chifres de um alce.

Talvez neste momento, um outro fator tenha começado a pesar na escolha das fêmeas: A potência sexual.

Segundo Reuben, tudo começou com o “crocodilo..." porque segundo explica, este foi o primeiro animal a desenvolver um pênis. Se é fato ou não, fica por conta do folclore.

Mas, se machos e fêmeas, antes disso apenas encostavam suas cloacas onde se contatavam óvulos e espermatozoides quase sem nada sentirem, a partir de então a relação sexual começou a ter outro sentido - $o$ despertar do prazer.

Nos milhares de anos de evolução, pênis, cloacas e vaginas foram se aperfeiçoando e se tornando cada vez mais receptivos e responsivos. Contudo, o compromisso fundamental ainda era - A reprodução para manutenção da espécie.

Quando surgiu o ser humano sobre a terra, ele captou essa mensagem e se engajou no processo, ativamente.

Procurou desenvolver suas aptidões e usá-las da melhor forma possível, para se afirmar junto à fêmea e garantir sua progênie. Como não possuísse atributos físicos que o tornasse vitorioso pela forca bruta (como garras, chifres, etc...), os primeiros hominídeos começaram a desenvolver rapidamente o cérebro, procurando encontrar soluções inteligentes quando o desafio se apresentava. Com relação ao instinto primário da Fome, ele desenvolveu artimanhas que lhe garantiam a caça e a sobrevivência, forjando armas e instrumentos de defesa. 
Com relação ao instinto primário do Sexo, ele passou a apresentar comportamentos mais ricos, quer seja exercendo uma autoridade firme, quer seja através de uma conduta mais participativa e protetora, ou se engalanando para se tornar sedutor. Era presente de um fruto mais saboroso ou de um quinhão de carne macia de uma caça, que serviam para o ritual da conquista.

Nas artimanhas da sedução, para ganhar a fêmea, o macho exibia seu sexo, cobertos muitas vezes de adornos para que ela se decidisse.

Por sinal em algumas culturas, era comum a incrustação de pedras preciosás e semipreciosas em torno da glande, o que impressionava as mulheres, não só pelo brilhantismo ofuscante das pedrarias, mas, melhor ainda, pelas conseqüências prazerosas que resultava dessa parafernália.

Parece que nesta época, ou melhor, nestas culturas, o mito do tamanho do pênis, ficava a dever ao mito do diâmetro do pênis, coisa aliás. que tem bem mais sentido.

Por sinal, ao estudarmos algumas formas primitivas de vida, encontramos também outras maneiras do macho atrair a atenção das fêmeas para seus genitais. Entre o os birmaneses por exemplo: há uma operação singular, que consiste em fazer pequenas incisões em torno da glande peniana onde são introduzidos minúsculos sinos de bronze, que tilintam enquanto durar o jogo sexual. Tudo faz crer que o apurado gosto musical das birmanesas se impressiona bastante com tal artificio, o que compensa qualquer esforço ou sacrifício por parte dos homens desse grupo.

Outros povos chegam a colocar pedaços de marfim, fragmentos de ouro e prata ou até pequenas varetas perpendiculares à glande do pênis, com o objetivo maior de, alargando sua extremidade, obter a preferência das mulheres.

Nas Filipinas e em Borneo, os homens usam anéis no pênis (como nos dedos) que servem de adorno e segundo eles, aumentam o prazer da mulher.

Algumas sociedades, porém, preconiza o uso de envoltórios penianos, chamados falocriptos, cujo objetivo primário é proteger e esconder o penis. Contudo. são tão exagerados nesta artimanha que chamam mais atenção a interesse sobre eles.

Ainda no século XIV eram comuns os envoltórios penianos, muitas vezes acolchoados e decorados com bordados, mas, que freqüentemente Procuravam assemelhar um pênis em ereção.

O fato é que, ainda hoje, o homem procura seduzir a mulher exibindo disfarçada ou despudoradamente seu instrumento fálico como tro- 
féu, mesmo que isto implique em usar subterfúgios ou técnicas milagrosas, anunciadas e que na maioria das vezes são perigosas e ineficientes.

Em todas essas práticas, porém, não fica claro o aumento do prazer para o homem. Parece que o objetivo de toda essa corte, inconscientemente tem sido, a conquista da fêmea e a garantia de sua progenitura. É o dedicado empenho para garantir a Vida sobre a terra e realizar a sua ânsia de eternidade.

É intrínseco ao ser humano esse desejo de eternidade, e o tato de que ele tem de enfrentar o implacável determinismo da Morte, impele-o a preservar a Vida a qualquer custo. Essa era a essência da filosofia primitiva e tribal.

Mas, não podemos esquecer também que o homem logo percebeu, que outras vantagens poderiam lhe advir como consequiência desse esforço, dessa sua luta ancestral. E a mãe natureza foi cúmplice...

Ela tratou de ser magnânima com o homem e o brindou com uma generosa paga. Dou-the a capacidade de usufruir prazer no exercício dessa tarefa, sem exigências nem castigos, mesmo quando ele tomava providências para ludibriá-la.

Permitiu também, que passada a época reprodutiva, já no ocaso da vida, o homem continuasse a viver prazerosamente dos encontros sexuais, quase como um brinde a quem se permitiu participar da grande obra da criação sobre a terra.

É evidente que isso exige empenho e esforço pessoal. Sabemos hoje, por fontes científicas fidedignas, que para o desempenho masculino persistir, a natureza lhe impõe uma maior dose de paciência, uma vez que lhe é exibido a manutenção da ereção, nem sempre tão fácil e nem sempre tão rápida. Por isso mesmo a partir dos 50 ou 60 anos, ele começa a buscar estímulos novos (parceiras novas, como solução imediatista) ou parte para o sacrifício das injeções penianas, quando não para o desespero das próteses penianas. Felizmente, para as mulheres, o problema é bem mais fácil. Existem hoje lubrificantes especiais que substitui com êxito os déficits de lubrificação, possibilitando-a de ter orgasmos gratificantes, e muitas vezes até episódios de multi-orgasmias quando perde o parceiro, ou fica à mercê de si própria, porque seu companheiro se esquiva ou não é capaz de lhe acompanhar, em face ao seu desempenho precário.

Daí, se conclui que o sexo, superando o aspecto reprodutivo, passou a ter também essa outra função, igualmente digna e naturalmente sabia: $A$ função prazerosa. 
Se a reprodução satisfazia a espécie, o prazer satisfaz ao indivíduo.

No início dessa fala, cheguei a afirmar que num sentido mais profundo, a vida em si tem uma ligação singular com a busca do prazer.

Com razão, diz Nathaniel Branden que "o prazer para os seres humanos, não é um luxo, mas, uma profunda necessidade psicológica. $\mathrm{O}$ prazer é, pois, um acessório metafísico da vida... E a recompensa a uma consequiência de uma ação bem sucedida...

De fato, através do Sexo, o homem obtém ganhos imediatos de prazer e gratificação inigualáveis, porque através dele nos tornamos "fonte direta e imediata, veículo e personificação do prazer". Descobrimos neste momento que a Felicidade é possível.

Para os taoístas, o Sexo deve ser desfrutado e sa-bo-re-a-do como um verdadeiro protetor da vida.

E é por isso que a negação do sexo entre os amantes é a ofensa maior, é a Dor maior que se pode infringir ao outro, porque atinge a própria estrutura vital do ser humano.

É importante também saber que a descoberta desse prazer ocorre muito precocemente na pessoa humana. Poderíamos dizer que, do ponto de vista evolutivo, isto ocorre em três etapas:

"O que sinto é bom "é a primeira etapa da evolução sexual afetiva do ser humano.

A descoberta da auto-aceitação e do amor a si mesmo, permite que o homem usufrua sem reservas, do prazer erótico. Há um imperativo egoístico, não resta dúvida, quando o indivíduo descobre seu potencial prazeroso e tenta explorá-lo, mas, qualquer outra forma que pretenda atingir o amadurecimento, tornar-se-á falha e improdutiva.

Nas culturas mais liberais a experiência sexual é aprovada a estimulada muito precocemente. Brincadeiras com o sexo não são punidas e dessa forma surgem poucos problemas de ajustamento sexual nos adultos.

Em outras culturas, como a nossa por exemplo: há muitas restrições, dificultando a evolução adequada da sexualidade.

Para alguns homens, o sexo permanece nesta etapa e continua a ser apenas um bom exercício, que libera as tensões e o acalma, predispondo para um bom dia de trabalho, ou uma repousante noite de sono. Para estes não há diferença entre a masturbação solitária ou na companhia de alguém. São masturbadores crônicos...

Mas, é preciso lembrar que sendo o homem um ser social, no seu processo evolutivo ele tende a descobrir que alguém pode ser fonte de prazer para si, iniciando-se aí, a vinculação com o outro. 
Há o que se pode chamar de Seleção Afetiva. Nas suas interrogações filosóficas, ele percebe o outro, e as necessidades que esse outro pode usufruir começam a tornar dimensões próprias. Descobre que o outro é capaz de alimentar suas necessidades de prazer.

Se no primeiro estágio ele é puro EROS, e como tal egoísta, ele agora começa a iniciar a busca do Filos, do afeto. $\mathrm{O}$ indivíduo pode parar nessa etapa, é claro. E assim usará o outro apenas enquanto o outro lhe for útil, o outro lhe der prazer e gratificações de acordo com suas expectativas. Mas, de um modo geral isso tem um preço.

De fato, nesta seleção afetiva, neste caminhar da sensualidade houve um crescimento e o paradigma passa a ser: "Gosto de você porque você me dá prazer... Você me reforça... Você me satisfaz! Você é bom para mim”.

Mas a tendência humana é de crescimento, e ao atingir esse estágio, ele começa a se inquietar, ele busca algo mais e podemos dizer que ele já está a caminho do Amor partilhado. E a Filosofia Existencial participativa encerra a idéia de abrir a Vida na direção do outro. É uma proposta de ampliar-se, de crescer...

Neste sentido dizemos que, se a atividade sexual por si só permite o prazer (o auto-erotismo), quando o homem sente receptividade e troca, esse prazer se amplia.

E é no jogo das trocas que ele se percebe crescendo. Trocas que ocorrem inicialmente no colo materno e no seio familiar, onde ele se prepara para o amor.

"A sexualidade primária, desnuda, desvincula desse sentimento que chamamos AMOR é boa, mas é pobre".

Ela conhece todas as fases e todas as faces do prazer humano, mas, é sexo sem amanhã.

Dizemos que é "Horizontalidade sem verticalidade".

Mas, o homem que anseia por seu evoluir bio-psíquico não pára neste estágio. Ele se inquieta e tenta se aprofundar no relacionamento. Ele sente a necessidade de eternizar, na brevidade de um momento, o gesto da entrega, numa vivência sexual perfeita. Assim, ele descobre o AMOR!

Nesta etapa de descoberta entre as pessoas, é comum acontecer um fenômeno singular - o apaixonamento, que é o primeiro passo na direção do Amor. Mas, amadurecer neste caminho exige tempo, atenção, envolvimento e determinação.

Sem esses cuidados, as coisas se atrapalham a se atropelam... 
Infelizmente temos observado que muitos casos de apaixonamento que poderiam ter evoluído para o AMOR, tem se perdido na confusão dos mal -entendidos, nos descaminhos do próprio AMOR.

Por que isso ocorre? perguntamos.

- Na verdade, ocorre porque vivenciar fases diferentes do crescimento humano é sempre algo difícil e doloroso.

Se passar do estágio primário do auto-erotismo para a descoberta do outro como fonte de prazer, exigiu esforço, muito maior será esse esforço quando caminharmos em direção a um prazer compartilhado. É preciso abrir-mão de alguns ganhos em favor do outro. Ouvir expectativas, dividir intimidades, ser paciente com as inseguranças e alegrar-se com as alegrias. É preciso respeitar valores e sentir que sua felicidade maior está em partilhar com o outro os momentos felizes.

Falamos então da descoberta do prazer que podemos proporcionar no outro. "Eu me sinto bem porque dou o bem a você", é a tônica.

Se agora a Sexualidade atingiu a dimensão do AMOR, pediríamos um tempo para falar nas etapas do amadurecimento desse Amor. Prometo não me alongar. Afinal tem se falado tanto em Amor que ele quase se prostituiu no linguajar comum.

Muitos afirmam "que fazem Amor", mas, poucos vivem realmente o AMOR. Para admitir o Amor é preciso amar-se. E se o pré-requisito do Amor é amar a si mesmo, a primeira etapa do Amor partilhado é o Apaixonamento.

O amor é um processo, a Paixão é uma etapa que desencadeia esse processo. A paixão estimula e exige a descoberta do outro. Quando isso ocorre mutuamente é um deslumbramento e é também uma motivação para que duas pessoas permaneçam juntas, tentando explorar sentimentos comuns, idéias e atividades comuns.

Num certo momento, quando a paixão é correspondida, os pares decidem interpretar seus sentimentos e planejar a vida juntos. É o momento da tomada de consciência, porque enquanto a emoção, a tesão pura e simples, é instintiva e reflexa, o sentimento passa pela corticalidade, exige comportamentos operantes para mantê-lo e fazê-lo crescer. Minha responsabilidade na escolha e no planejamento do meu futuro estará em Jogo.

Esse planejamento estará também moldado em arranjos que satisfaçam a ambos os parceiros, e por isso mesmo varia segundo as necessidades e o momento sócio-cultural em que se vive. 
Algumas vezes existem acertos contratuais de ordem religiosa ou legal. Outras vezes o contrato fica para segundo plano porque dentro da filosofia de vida do par, isto é desnecessário. Em qualquer das hipóteses, sempre haverá acordos mútuos nesta mini-sociedade.

No arrebatamento da Paixão os pares vivenciam a lua de mel, que embora cheia de beleza e romantismo, nem por isso é sólida e definitiva.

Esse Amor nascente, para crescer precisará ser cultivado. Se não houver cultivo, o Amor morre com o fim da Paixão que o gerou.

A decisão de investir no Amor é pessoal e envolve uma infinidade de variáveis.

$\mathrm{Na}$ verdade, a Paixão inicia o processo, ao qual eu decido pôr fim, porque outros interesses e valores estão em jogo.

Há pessoas até que preferem permanecer num clima de apaixonamento constante, satisfazendo-se com deslumbramentos contínuos a seqüenciais. Desistem de desenvolver o Amor. Para elas, viver neste clima é o bastante, e na verdade, muitas vezes tem suas vantagens.

Parece que esta tem sido a tônica de nossa sociedade de consumo e altamente descartável em que vivemos. Até a Paixão e o Amor tornaram-se descartáveis.

Não vamos aqui aquilatar o valor dessas decisões, nem julgá-las como melhor ou pior. São decisões pessoais e altamente respeitáveis, só que não podem ser confundidas com Amor. Como diz Solomon: "O Amor é algo mais..." embora comece da mesma forma.

E como então caracterizar os ingredientes do processo do Amor?

Paixão (romance, fantasia)

Amizade e Sexo-Comunicação.

É evidente que, se o Amor começa com a Paixão, isso envolve excitação, atração mútua. Mas, a atração é curta, enquanto o Amor tende a ser longo...

A atração inicia o romance, sem o qual o Amor não subsiste. E é este romance que vai estimular a fantasia, ingrediente altamente necessário à criatividade amorosa. Já se disse que as pessoas que possuem imaginação fértil, ama melhor. Isto ocorre porque há um contínuo recriar interior.

Mesmo que o dia a dia seja prosaico, mesmo que o parceiro(a) tenha dificuldade de renovação interna, o parceiro romântico estará atento para não deixar se extinguir o processo renovador do Amor.

E, alimentar a Fantasia não é se alienar porque Fantasia não é ilusão, nem é antítese da realidade pura e simplesmente. Isto seria simplório demais e tugiria à Verdade.

Fantasia, como parte integrante do romance amoroso é o enriquecimento da realidade. Daí porque, quem ama se sente rico... 
Neste caso, as melhores fantasias são aquelas que podem ser compartilhadas, embora às vezes, a prudência aconselhe a evitar tal artificio.

Para que a partilha da Fantasia seja saudável, é necessário existir um clima de comunicação visceral entre os parceiros. Nem sempre nosso parceiro tem maturidade suficiente para que isso ocorra. Outras vezes, ele prefere ficar imune ao apelo, entrando no processo degenerativo do Desamor.

Outro ingrediente fundamental ao Amor é a AMIZADE. Ela complemente e reforça o Amor, fazendo-o durar. A amizade suaviza a ao mesmo tempo solidifica o Amor.

Maria Helena Matarazzo diz com razão que: “Amar significa ser amigos íntimos".

A amizade leva ao respeito pela individualidade do outro a ajuda também no processo comunicativo, no processo do ENCONTRO.

E... comunicação e encontro é imprescindível a todo relacionamento humano sadio.

Comunicação é a pedra angular e o sangue vital de uma relação.

Os casais que não se comunicam não conseguem manter a intimidade tão necessária ao Amor. Sem comunicação extingue-se a cumplicidade amorosa.

E aqui chegamos ao ponto crucial de nossa fala: A comunicação como via, como caminho perfeito para se atingir uma sexualidade plena, para se atingir o ENCONTRO CÓSMICO.

Neste sentido, o Sexo pode ser entendido como a forma mais íntima e profunda da Comunicação Humana.

Sexo - Comunicação Amorosa é o somatório de todos os aspectos parciais da sexualidade. $\mathrm{O}$ feed-back amoroso retroalimentando informações, amplia a própria estimulação erótica. Ele exicge comunicação verbal e gestual e facilita essa mesma comunicação.

Neste sentido o sexo deixa de ser um comportamento estereotipado e estanque, deixa de ser apenas uma ginástica mirabolante, e passa a ser toda uma forma de sentir, pensar a querer. Ele se torna a própria expressão do Amor, onde o toque, o carinho, passam a ter um significado profundo. Se estivermos realmente envolvidos com a sexualidade como expressão de vida, encontraremos o verdadeiro caminho para o Amor. E é nesse "dar as mãos" que se descobre valores e objetivos comuns. 
Desaparece aí o perigo da fossilização. Abrem-se as portas para as descobertas mútuas, possibilitando um sexo sempre renovado, num contexto de Amor maduro, constantemente recriado. E é a comunicação que quebra as arestas e salva a sexualidade, mesmo em declínio. Quando a comunicação se interrompe, ouve-se apenas seus próprios apelos, a ocorre a regressão aos processos iniciais do prazer, onde o egoísmo e o egocentrismo tornam-se a tônica. $\mathrm{O}$ amor fica aviltado.

E nós sabemos que Amor sem sexo é sempre uma forma truncada de Amor. Daí porque a harmonia sexual é um fator essencial ao Amor.

No processo de aprendizagem porém, para que o encaixe se torne perfeito deve se levar em conta os gostos, as preferências sexuais.

E é mais uma vez o diálogo, a comunicação verdadeira que vai facilitar esse encaixe. Com razão se diz que "O Amor faz o Sexo durar", mas a contrapartida é igualmente verdadeira: "O bom sexo ajuda o Amor a durar".

No final dessas considerações quero deixar bem claro que não pretendi dar receitas, ou estipular regras para o Amor. Não pretendi também dizer que o Amor segue um único traçado, um único Caminho, porque para cada um de nós, para cada um de vocês, ele é e será sempre uma experiência pessoal e única que necessita mais do que nunca ser vivenciado a reinventado a cada dia. Os caminhos e descaminhos desse Amor é responsabilidade de cada um de nós.

Quantas vezes nesse caminhar perdemos os rumos e isso pode ocorrer em qualquer momento do trajeto amoroso. Há pessoas que se desencontram na infância do Amor, não permitindo que ele cresça e tome corpo. São amores curtos e fortuitos.

Outros deixam fenecer o Amor na adolescência ou na idade adulta. Não são capazes de superar as crises, porque o diálogo se interrompeu em qualquer das direções. E comunicação exige disponibilidade dos dois.

Mas, o mais trágico ainda, é assistir a um Amor Maduro, pleno de riqueza - onde o crescimento mútuo foi a tônica -, deixar se perder no reboliço estéril de um modismo, onde a ilusão do prazer fácil e egoísta, destrói a própria estrutura do Amor. Este me parece ser o mais cruel e trágico dos desfechos, que infelizmente temos assistido neste final de milênio, onde grandezas e misérias se misturam.

O desafio do Amor tem exigido muito das pessoas de boa vontade, de caráter firme e de maturidade consciente, para que ele permaneça íntegro e ético. 
Isso é um trabalho lento, progressivo e por vezes doloroso, com formas diversas de funcionamento, cuja dinâmica psicológica requer auto-transformação constante e zelo contínuo, e onde o tempo não se mede pelo número de anos de convivência porque o Amor traz o tempo em si mesmo. Amor requer maturidade interna. E é talvez por isso, que o poeta brasileiro, Drummond de Andrade, sabiamente escreveu:

"Amor é privilégio de maduros Amor começa tarde..."

\section{BIBLIOGRAFIA}

1. Áries, P. e Béjim, A. (orgs.). Sexualidades ocidentais, Brasiliense, 1982.

2. Berne, Eric. Sexo e amor, José Olímpio, 1976.

3. Braden, Nathaniel. A psicologia do amor romântico, Imago, RJ, 1982.

4. Cavalcanti, M. Afeto, amor e sexualidade, In: Sexologia II, Roca, 1986.

5. Cavalcanti, Ricardo. A história natural do amor, Ed. Gente, 1995.

6. Cunha, P. Sexamor, Nórdica, 1982.

7. Ellis, H. A seleção natural do homem, Civ. Brasileira, 1935.

8. Gregersen, E. Práticas sexuais, Roca, 1983.

9. Hunt, M. História natural do amor, Ibrasa, 1963.

10. May, Rollo. Psicologia existencial, Globo, RJ, 1988.

11. Matarazzo, M. H. Amar é preciso, Ed. Gente, 1992.

12. Mussen, P. O desenvolvimento psicológico da criança, Zahar, 1975.

13. O'Connor, D. Como hacer el amor... con amor!!!

14. Penney, A. Amor total, Best Seller, 1982.

15. Reuben, D. Toda mulher pode, Record, 1971.

16. Solomon, R. $O$ amor, Saraiva, 1992. 